\title{
Comment on Publications from OpT2mise Study
}

\author{
National Diabetes Committee of Republic of Macedonia: Tatjana Milenkovic, MD, PhD, \\ Mirjana Kocova, MD, PhD, Brankica Krstevska, MD, PhD, Gordana Pemovska, MD, PhD, \\ and Ivica Smokovski, MD, PHD
}

\section{Dear Editor:}

T IS WELL KNOWN THAT THE TYPE 2 diabetes "pandemic" is spreading relentlessly throughout the world, and the Republic of Macedonia is certainly not an exception: according to the latest International Diabetes Federation Atlas data from 2015, the country is occupying the unpopular third place in Europe in terms of diabetes comparative prevalence (10.3\%), with the vast majority of cases (approximately 98\%) diagnosed with type 2 diabetes. ${ }^{1}$ Many factors have contributed to such a high prevalence of type 2 diabetes in the country, including the considerable rise in caloric intake per capita with no concurrent physical activity, ${ }^{2}$ very high smoking prevalence, ${ }^{3}$ and the transition from a socialist to a market economy with jobs and income insecurity-leading to steep rise in unemployment and associated stress. Such an explosion of type 2 diabetes has been among the main reasons for categorization of the Republic of Macedonia as a very high-risk country in Europe in terms of cardiovascular mortality. ${ }^{4}$ Consequently, type 2 diabetes prevalence in the country and worldwide has been associated with alarming socioeconomic effects: approximately $40 \%$ of the country's total budget for all reimbursed nonhospital medications was spent only on insulin, glucometers, test strips, glucagon, insulin needles, insulin pumps, and related supplies, provided free through a government program, not including oral antidiabetes drugs or other direct and indirect diabetes-related costs. ${ }^{5,6}$

The recently adopted Law on Healthcare Amendment addresses diabetes mellitus as a specific medical condition posing a serious threat to the whole society. ${ }^{7}$ In addition, international guidelines were adopted as national diabetes guidelines and were published in the Official Journal of the country, where typically laws and by-laws are published. ${ }^{8}$ The Law on Healthcare Amendment also stipulated formation of the National Diabetes Committee, responsible for the national diabetes care policy and strategy as well as for ensuring adherence to the national diabetes guidelines by various stakeholders, including the evaluation of electronic healthcare records. ${ }^{7}$

According to the national diabetes guidelines, treatment with insulin pumps (continuous subcutaneous insulin infusion [CSII]) is not recommended in type 2 diabetes patients in the Republic of Macedonia, and insulin pumps and related supplies provided free of charge through the Government
Program are aimed exclusively for type 1 diabetes patients, as has been recommended and applied elsewhere. ${ }^{8,9}$

The University Clinic of Endocrinology, Diabetes and Metabolic Disorders from the Republic of Macedonia was one of the European centers participating in the OpT2mise clinical study - a multicenter, international, randomized, controlled, parallel-group study to evaluate the comparative efficacy and safety of CSII and multiple daily injection regimens in insulin-using patients with type 2 diabetes who were suboptimally controlled with advanced basal-bolus therapy. ${ }^{10-13}$

After the patients treated with CSII in the Republic of Macedonia were evaluated, the National Diabetes Committee was officially informed by the University Clinic of Endocrinology, Diabetes and Metabolic Disorders that at least 13 type 2 diabetes patients were treated with insulin pumps and supplies through the government program, after completing their participation in a clinical study with CSII in type 2 diabetes patients. ${ }^{10-13}$ Once their treatment was reviewed, the National Diabetes Committee decided that those patients should no longer be treated with CSII in accordance with the national diabetes guidelines and should be switched to insulin pen therapy instead.

After this decision, several of the affected patients directly approached the National Diabetes Committee confirming that they had participated in the clinical study with CSII; however, they claimed they had never been diagnosed with type 2 diabetes, but rather with type 1 diabetes.

National Diabetes Committee thoroughly examined the electronic health records of all 13 patients from the National eHealth System and found that all 13 of them had a record of type 1 diabetes diagnosis during the study duration, despite the fact that the clinical study inclusion criteria, both at screening and at randomization, were limited to patients diagnosed with type 2 diabetes mellitus, as per the investigator's discretion. Some of those patients were found to also have a record of type 2 diabetes diagnosis, mainly after study completion; however, at least three patients had a record of only type 1 diabetes in the National eHealth System even after study completion, up to the date of review (January 15, 2016).

The responsible physician acting as national Principal Investigator in the mentioned study was asked by the National Diabetes Committee for an explanation of these findings in 
numerous occasions; however, no reasonable explanation was received.

It is our concern that such findings might have an impact on the study results and conclusions as presented in the recent publications, given the portion of patients enrolled from the Republic of Macedonia out of the total number of reported patients randomized on CSII $(n=168) .{ }^{10-13}$ Taking into consideration the differences in the pathogenesis between type 1 and type 2 diabetes, as well as in the use of pump therapy and overall management as recognized by the study authors, ${ }^{10-13}$ we believe that inappropriate inclusion of type 1 diabetes patients in the clinical study with CSII in type 2 diabetes patients is a violation of inclusion criteria, might affect the hypothesis of studying CSII in the largest homogeneous cohort of type 2 diabetes patients, and might distort the study results and lead to misrepresenting conclusions. These patients should be reevaluated by the international Principal Investigator for the whole international study in order to check and confirm the published results in several studies published in journals with significant impact factor.

The National Diabetes Committee firmly believes that newer treatments are essential for achieving improved glycemic control in type 2 diabetes patients and strongly encourages clinical research in this area through multinational, multicenter, randomized, controlled clinical studies. We already are experiencing numerous advanced treatments for type 2 diabetes patients and are expecting even more to be available, including the method of CSII as a viable option for type 2 diabetes patients. However, we believe that these data should be based on sound scientific evidence and should certainly not be based on incorrect patient recruitment.

Our role to protect the health and well-being of diabetes patients from the Republic of Macedonia, including type 2 diabetes patients, as well as the healthcare resources required for sustainable diabetes care, necessitates that we also contribute toward providing scientifically sound clinical data for the benefit of all type 2 diabetes patients in Republic of Macedonia, and throughout the world. Additionally, we encourage strict adherence to the highest standards of Good Clinical Practice in international, multicenter clinical studies to ensure generation of credible and verifiable clinical data that might impact the recommendations in diabetes clinical guidelines worldwide.

Therefore, we believe that our concerns relevant for the patients enrolled in the clinical study from the Republic of Macedonia should strongly be considered while interpreting the OpT2mise clinical study's results and conclusions. We remain open and available for any additional requests or queries that might arise.

\section{References}

1. International Diabetes Federation: IDF Diabetes Atlas, $7^{\text {th }}$ edition. Brussels: International Diabetes Federation, 2015.
2. Food and Agriculture Organization of the United Nations, Statistics Division. Food Balance. 2015. http://faostat3.fao. org/browse/FB/*/E (accessed January 19, 2016).

3. Ng M, Freeman M, Fleming T, et al.: Smoking prevalence and cigarette consumption in 187 countries, 1980-2012. JAMA 2014;311:183-192.

4. Perk J, De Backer G, Gohlke H, et al.: European Guidelines on cardiovascular disease prevention in clinical practice (version 2012). The Fifth Joint Task Force of the European Society of Cardiology and Other Societies on Cardiovascular Disease Prevention in Clinical Practice. Eur Heart J 2012;33:1635-1701.

5. Healthcare Insurance Fund of Republic of Macedonia: Annual Report for 2014. www.fzo.org.mk/default.asp?ItemID= E47E1E538B68294BB0A1077B2DAFA4D9 (accessed January 19, 2016).

6. Ministry of Health of Republic of Macedonia: Program for providing insulin, glucagon, insulin needles, test strips for glycaemia, and education for treatment and control of diabetes [in Macedonian]. Official J Republic Macedonia 2014;196:78-80.

7. Law for Amendments of Law on Healthcare [in Macedonian]. Official J Republic Macedonia 2015;10:41-42.

8. Healthcare guidelines on treatment and control of type 2 diabetes [in Macedonian]. Official J Republic Macedonia 2015;40:15-34.

9. National Institute for Health and Care Excellence: Continuous Subcutaneous Insulin Infusion for the Treatment of Diabetes Mellitus. Technology Appraisal Guidance. https:// www.nice.org.uk/guidance/ta151 (accessed January 19, 2016).

10. Aronson R, Cohen O, Conget I, et al.: OpT2mise: a randomized controlled trial to compare insulin pump therapy with multiple daily injections in the treatment of type 2 diabetes-research design and methods. Diabetes Technol Ther 2014;16:414-420.

11. Reznik Y, Cohen O, Aronson R, et al.: Insulin pump treatment compared with multiple daily injections for treatment of type 2 diabetes (OpT2mise): a randomised open-label controlled trial. Lancet 2014;384:1265-1272.

12. Reznik Y, Huang S; OpT2mise Study Group: Reductions in A1C with pump therapy in type 2 diabetes are independent of C-peptide and anti-glutamic acid decarboxylase antibody concentrations. Diabetes Technol Ther 2014; 16:816-818.

13. Conget I, Castaneda J, Petrovski G, et al.: The impact of insulin pump therapy on glycemic profiles in patients with type 2 diabetes: data from the OpT2mise Study. Diabetes Technol Ther 2016;18:22-28.

Address correspondence to: National Diabetes Committee of Republic of Macedonia Vodnjanska 17 Skopje, MK 1000, Republic of Macedonia E-mail: dijabetes@zdravstvo.gov.mk 